\title{
Study on Larvicidal Effect of Different Plant Parts of Milk Weed Plant (Calotropis gigantea R. Br.) against Helicoverpa armigera
}

\author{
S. Prabhu*", P. Priyadharshini and A. Thangamalar \\ Department of Sericulture, Forest College and Research Institute, TNAU, \\ Mettupalayam, Tamil Nadu, India \\ *Corresponding author
}

\author{
A B S T R A C T
}

\begin{tabular}{|l|}
\hline Ke y w o r d s \\
Milk weed plant, \\
Larvicidal effect, \\
Aqueous, \\
Helicoverpa \\
armigera.
\end{tabular}

The larvicidal property of aqueous extracts of different plant parts of milk weed plant viz., leaves, stem, flower and roots were studied on III, IV, V instar larval stages of the Helicoverpa armigera at two, four, six, eight and 10 per cent concentrations. The results indicated the five plant parts extract caused significant larval mortality. But the mortality was the maximum $(80.00 \%)$ when aqueous leaf extract at 10 per cent concentration was used on second instar larvae of $H$. armigera. The mortality rate was high in second instar larvae and gradually decreased in the third, fourth and fifth instars larvae. As the larvae became older, the mortality was nil in the fifth instar larvae. In leaf extract, the mortality per cent got reduced from 83.33 to 76.66 per cent in third instar and 63.33 per cent in fourth instar. The flower extract was treated on different larval instars at various concentrations and from the results, it was observed that 10 per cent extract caused larval mortality to an extent of 66.66, 53.33 and 20.00 per cent on third, fourth and fifth instars respectively. The root extract was less effective and caused 36.66 per cent mortality in second instar. This percentage got reduced when it was treated on the succeeding larval instars, namely third, fourth and fifth instar. The whole plant extract showed greater mortality next to leaf and flower extract at 10 per cent concentration and caused larval mortality to an extent of $63.33,46.66$ and 16.66 per cent on third, fourth and fifth instar.

\section{Introduction}

Helicoverpa armigera Hubner (Lepidoptera: Noctuidae) is considered to be an important pest, since they are capable of wiping out the entire crop (Pawar, 1998). An annual loss of about Rs. 2,000 crores by Helicoverpa armigera (Ignacimuthu and Jayaraj, 2003) is incurred in India. $H$. armigera is a polyphagous and attacking 96 cultivated and 61 uncultivated plants widely distributed in most of the Asian countries. The major susceptibles include cotton, pulses, oilseeds, millets and vegetables (Reed and Pawar,
1982). The host record is diverse and few botanicals were suggested for its management (Koul et al., 2002; Sahayaraj et al., 2007). Further, this destructive pest is known to have developed resistance against most of the recommended insecticides (Kranthi et al., 2001; Ramasubramanyam, 2004). However, to promote ecological balance and to minimize the insect resistance to insecticides, it is necessary to shift to integrated management of pests (Ravi et al., 2008). Certain plants by nature possess secondary 
metabolites, which act as antifeedants, oviposition deterrents, larvicidal and insect growth regulators (Vasantharaj David, 2008) as well as effective against plant pathogens (Harborne, 1988). Moreover, botanicals are preferred over other methods since they are easily available, biodegradable and least toxic to non-target organisms (Wink and Guo, 1995). In the present study, in order to find a new botanical based biopesticide for the management of Helicoverpa armigera, larvicidal effect of milk weed plant was evaluated.

\section{Materials and Methods}

\section{Collection of plant materials and preparation of milk weed plant extract}

The whole plants of milk weed plant (Calotropis gigantea R. Br.) distributed in waste lands were collected, washed and dried in shade. The shade drying process was continued until the plant materials were dried enough to be powdered. The dried plant parts viz., leaves, stem, flower and roots were powdered using willey mill and stored in air tight containers at $4{ }^{\circ} \mathrm{C}$ for further use. Whole plant powder was prepared by mixing leaf, flower, stem and root powder in equal proportions. One gram of powder was first dissolved in $100 \mathrm{ml}$ of water (stock solution) and from the stock solution, 2, 4, 6, 8 and 10 per cent concentrations were prepared with dechlorinated tap water.

\section{Mass culturing of Helicoverpa armigera}

The eggs of $H$. armigera were collected from the field, transferred on a piece of cloth and after surface sterilization (with $0.1 \%$ sodium hypochlorite solution) kept on plastic trays. The emerged neonates were transferred to the chickpea plant using a fine camel hairbrush. When the larvae were four to five days old (second instar), they were transferred to multicavity tray containing fresh bhendi fruit pieces to avoid cannibalism (Ballal et al., 1998). The larvae were allowed to remain in the multicavity tray until they reached the prepupal stage and then transferred to sand medium for pupation. The pupae obtained from culture were placed in petridishes inside adult emergence cage. Adults were fed with 10 per cent sucrose solution mixed multi vitamin drops. Ten pairs of healthy adults were transferred to plastic buckets for mating and oviposition. The top of plastic bucket was covered with sterile blue coloured muslin cloth, which served as an oviposition substrate.

Larvicidal action of $C$. gigantea plant parts extracts on different larval stages of $H$. armigera

The insecticidal property of aqueous extracts were studied on III, IV, V instar larval stages of the $H$. armigera at two, four, six, eight and 10 per cent concentrations. Topical application of plant extract on the test insect was done by using an atomizer and replicated thrice for each instar. Thirty insects were taken per replication. After applying, the insects were maintained in a plastic container separately with bhendi fruits. The treated insects were observed up to $72 \mathrm{hrs}$ and the percentage of mortality was recorded (Sahayaraj and Gabriel, 1998).

\section{Results and Discussion}

Use of synthetic pesticides causes some unfortunate consequences such as environmental pollution, pests' resistance and toxicity to other non-target organisms including human being. Chemical pollution by pesticides has been increasing in a large scale due to their vast usage for eradication of various pests and insects and to protect agricultural crops. Developed countries and developing countries which are progressing 
rapidly in the field of agriculture, technology and industry are introducing various kinds of harmful substance into the biosphere and thereby facing serious challenges in the form of environmental pollution. The use of botanicals in crop protection has now gained a popular ground in the world of agriculture as an alternative to toxic, persistent and synthetic compounds. Plants produce more phytochemicals that specifically inhibit growth, morphogenesis, metamorphosis and reproduction in insects (Ahmad, 2007).

Larvicidal activity of aqueous extract of leaf, flower, stem, root and whole plant of $C$. gigantea against different larval stages of $H$. armigera are reported in Table 1. Mortality tended to decline with increasing larval age, and significant differences were recorded between the instars.

\section{Larvicidal activity on third instar}

The leaf extract was found to be most toxic followed by flower, stem, root and whole plant among the various plant parts tested for the instars. Leaf extract @ 10 per cent caused the highest mortality of 76.66 per cent, while 63.33 per cent mortality was recorded in 8 per cent concentration. The flower extract at 10 per cent registered high mortality $(66.66 \%)$ next to leaf extract followed by 8 per cent $(53.33 \%)$, six per cent $(36.66 \%)$, four per cent $(23.33 \%)$ and two per cent (16.66\%). Stem extract exerted maximum mortality of 33.33 per cent in 10 per cent concentration. With respect to root extract, two per cent showed least mortality of 6.66 per cent. The whole plant extracts caused highest mortality of 63.33 per cent in 10 per cent concentration followed by eight per cent $(46.66 \%)$, six per cent $(33.33 \%)$ and four per cent $(20.00 \%)$. Ramos et al., (2006) showed that the $C$. procera latex contains the larvicidal compounds, which caused $100 \%$ mortality in III stage larvae of A. egypti.

\section{Larvicidal activity on fourth instar}

Leaf extract at 10 per cent concentration recorded 63.33 per cent mortality. This was followed by $8,6,4$ and 2 per cent concentrations recording 56.66, 33.33, 20.00 and 16.66 per cent mortality respectively. Flower extracts at two and four per cent were on par with each other showing 13.33 per cent mortality each while 10 per cent concentration recorded highest mortality of 53.33 per cent followed by eight per cent $(43.33 \%)$ and six per cent $(23.33 \%)$ mortality. With regard to stem extract, 10 per cent showed 26.66 per cent mortality, while the mortality ranged from 6.66-23.33 per cent for concentrations between two and eight per cent.

Root extract recorded low mortality compared to leaf, flower and stem extracts wherein two and four per cent concentrations showed 3.33 and 6.66 per cent mortality respectively. Whole plant extract at 10 per cent recorded a mortality of 46.66 per cent.

\section{Larvicidal activity on fifth instar}

Among the aqueous extract of $C$. gigantea plant parts tested, the maximum mortality of $H$. armigera was recorded at 10 per cent leaf extract $(36.66 \%)$ which was on par with eight per cent concentration followed by six per cent $(20.00 \%)$, four per cent $(13.33 \%)$ and two per cent $(6.66 \%)$. Flower extracts at two and four per cent showed least mortality of 3.33 and 6.66 per cent respectively and 10 per cent concentration showed 20.00 per cent mortality. Stem and root extracts at two and four per cent showed no mortality. Whole plant extracts at two and four per cent recorded 3.33 per cent mortality and were on par with each other, while 10 per cent concentration caused maximum mortality of 16.66 per cent followed by eight per cent $(13.33 \%)$. 
Table.1 Larvicidal action of aqueous extract of leaf, flower, stem, root and whole plant of $C$. gigantea on different stages of larvae of $H$. armigera

\begin{tabular}{|c|c|c|c|c|c|c|c|c|c|c|c|c|c|c|c|}
\hline \multirow[t]{3}{*}{ Treatments } & \multicolumn{15}{|c|}{ Mortality in Percentage* } \\
\hline & \multicolumn{5}{|c|}{ III instar } & \multicolumn{5}{|c|}{ IV instar } & \multicolumn{5}{|c|}{$\mathrm{V}$ instar } \\
\hline & Leaf & Flower & Stem & Root & $\begin{array}{c}\text { Whole } \\
\text { plant }\end{array}$ & Leaf & Flower & Stem & Root & $\begin{array}{c}\text { Whole } \\
\text { plant }\end{array}$ & Leaf & Flower & Stem & Root & $\begin{array}{c}\text { Whole } \\
\text { plant }\end{array}$ \\
\hline $2 \%$ & $\begin{array}{c}23.33 \\
(28.78)^{\mathrm{e}}\end{array}$ & $\begin{array}{c}16.66 \\
(23.85)^{\mathrm{e}}\end{array}$ & $\begin{array}{c}10.00 \\
(18.43)^{\mathrm{e}}\end{array}$ & $\begin{array}{c}6.66 \\
(13.64)^{\mathrm{e}}\end{array}$ & $\begin{array}{c}13.33 \\
(21.14)^{\mathrm{e}}\end{array}$ & $\begin{array}{c}16.66 \\
(23.85)^{\mathrm{e}}\end{array}$ & $\begin{array}{c}13.33 \\
(21.14)^{\mathrm{d}}\end{array}$ & $\begin{array}{c}6.66 \\
(13.64)^{\mathrm{e}}\end{array}$ & $\begin{array}{c}3.33 \\
(8.84)^{\mathrm{e}}\end{array}$ & $\begin{array}{c}10.00 \\
(18.43)^{\mathrm{e}}\end{array}$ & $\begin{array}{c}6.66 \\
(13.64)^{\mathrm{d}}\end{array}$ & $\begin{array}{c}3.33 \\
(8.84)^{\mathrm{e}}\end{array}$ & $\begin{array}{c}0.00 \\
(0.0)^{\mathrm{d}}\end{array}$ & $\begin{array}{c}0.00 \\
(0.0)^{\mathrm{c}}\end{array}$ & $\begin{array}{c}3.33 \\
(8.84)^{\mathrm{d}}\end{array}$ \\
\hline $4 \%$ & $\begin{array}{c}26.66 \\
(30.99)^{\mathrm{d}}\end{array}$ & $\begin{array}{c}23.33 \\
(28.78)^{\mathrm{d}}\end{array}$ & $\begin{array}{c}16.66 \\
(23.85)^{d}\end{array}$ & $\begin{array}{c}13.33 \\
(21.14)^{\mathrm{d}}\end{array}$ & $\begin{array}{c}20.00 \\
(26.56)^{\mathrm{d}}\end{array}$ & $\begin{array}{c}20.00 \\
(26.56)^{\mathrm{d}}\end{array}$ & $\begin{array}{c}13.33 \\
(21.14)^{\mathrm{d}}\end{array}$ & $\begin{array}{c}10.00 \\
(18.43)^{\mathrm{d}}\end{array}$ & $\begin{array}{c}6.66 \\
(13.64)^{d}\end{array}$ & $\begin{array}{c}13.33 \\
(21.14)^{\mathrm{d}}\end{array}$ & $\begin{array}{c}13.33 \\
(21.14)^{\mathrm{c}}\end{array}$ & $\begin{array}{c}6.66 \\
(13.64)^{\mathrm{d}}\end{array}$ & $\begin{array}{c}0.00 \\
(0.0)^{\mathrm{d}}\end{array}$ & $\begin{array}{c}0.00 \\
(0.0)^{\mathrm{c}}\end{array}$ & $\begin{array}{c}3.33 \\
(8.84)^{\mathrm{d}}\end{array}$ \\
\hline $6 \%$ & $\begin{array}{c}43.33 \\
(41.15)^{\mathrm{c}}\end{array}$ & $\begin{array}{c}36.66 \\
(37.22)^{\mathrm{c}}\end{array}$ & $\begin{array}{c}23.33 \\
(28.78)^{\mathrm{c}}\end{array}$ & $\begin{array}{c}20.00 \\
(26.56)^{\mathrm{c}}\end{array}$ & $\begin{array}{c}33.33 \\
(35.21)^{\mathrm{c}}\end{array}$ & $\begin{array}{c}33.33 \\
(35.21)^{\mathrm{c}}\end{array}$ & $\begin{array}{c}23.33 \\
(28.78)^{\mathrm{c}}\end{array}$ & $\begin{array}{c}13.33 \\
(21.14)^{\mathrm{c}}\end{array}$ & $\begin{array}{c}10.00 \\
(18.43)^{\mathrm{c}}\end{array}$ & $\begin{array}{c}20.00 \\
(26.56)^{\mathrm{c}}\end{array}$ & $\begin{array}{c}20.00 \\
(26.56)^{\mathrm{b}}\end{array}$ & $\begin{array}{c}13.33 \\
(21.14)^{\mathrm{c}}\end{array}$ & $\begin{array}{c}6.66 \\
(13.64)^{\mathrm{c}}\end{array}$ & $\begin{array}{c}3.33 \\
(8.84)^{\mathrm{b}}\end{array}$ & $\begin{array}{c}10.00 \\
(18.43)^{\mathrm{c}}\end{array}$ \\
\hline $8 \%$ & $\begin{array}{c}63.33 \\
(52.77)^{\mathrm{b}}\end{array}$ & $\begin{array}{c}53.33 \\
(46.92)^{\mathrm{b}}\end{array}$ & $\begin{array}{c}30.00 \\
(33.21)^{\mathrm{b}}\end{array}$ & $\begin{array}{c}26.66 \\
(30.99)^{b}\end{array}$ & $\begin{array}{c}46.66 \\
(43.07)^{\mathrm{b}}\end{array}$ & $\begin{array}{c}56.66 \\
(48.92)^{\mathrm{b}}\end{array}$ & $\begin{array}{c}43.33 \\
(41.15)^{\mathrm{b}}\end{array}$ & $\begin{array}{c}23.33 \\
(28.78)^{\mathrm{b}}\end{array}$ & $\begin{array}{c}16.66 \\
(23.85)^{\mathrm{b}}\end{array}$ & $\begin{array}{c}36.66 \\
(37.22)^{\mathrm{b}}\end{array}$ & $\begin{array}{c}33.33 \\
(32.21)^{\mathrm{a}}\end{array}$ & $\begin{array}{c}16.66 \\
(23.85)^{\mathrm{b}}\end{array}$ & $\begin{array}{c}10.00 \\
(18.43)^{\mathrm{b}}\end{array}$ & $\begin{array}{c}3.33 \\
(8.84)^{\mathrm{b}}\end{array}$ & $\begin{array}{c}13.33 \\
(21.14)^{\mathrm{b}}\end{array}$ \\
\hline $10 \%$ & $\begin{array}{c}76.66 \\
(61.21)^{\mathrm{a}}\end{array}$ & $\begin{array}{c}66.66 \\
(54.78)^{\mathrm{a}}\end{array}$ & $\begin{array}{c}33.33 \\
(35.21)^{\mathrm{a}}\end{array}$ & $\begin{array}{c}30.00 \\
(33.21)^{\mathrm{a}}\end{array}$ & $\begin{array}{c}63.33 \\
(52.77)^{\mathrm{a}}\end{array}$ & $\begin{array}{c}63.33 \\
(52.77)^{\mathrm{a}}\end{array}$ & $\begin{array}{c}53.33 \\
(46.92)^{\mathrm{a}}\end{array}$ & $\begin{array}{c}26.66 \\
(30.99)^{\mathrm{a}}\end{array}$ & $\begin{array}{c}23.33 \\
(2878)^{\mathrm{a}}\end{array}$ & $\begin{array}{c}46.66 \\
(43.07)^{\mathrm{a}}\end{array}$ & $\begin{array}{c}36.66 \\
(37.22)^{\mathrm{a}}\end{array}$ & $\begin{array}{c}20.00 \\
(26.56)^{\mathrm{a}}\end{array}$ & $\begin{array}{c}13.33 \\
(21.14)^{\mathrm{a}}\end{array}$ & $\begin{array}{c}6.66 \\
(13.64)^{\mathrm{a}}\end{array}$ & $\begin{array}{c}16.66 \\
(23.85)^{\mathrm{a}}\end{array}$ \\
\hline Control & $0.0(0.0)^{\mathrm{f}}$ & $\begin{array}{c}0.0 \\
(0.0)^{\mathrm{f}}\end{array}$ & $\begin{array}{c}0.0 \\
(0.0)^{\mathrm{f}}\end{array}$ & $\begin{array}{c}0.0 \\
(0.0)^{\mathrm{f}}\end{array}$ & $\begin{array}{c}0.0 \\
(0.0)^{\mathrm{f}}\end{array}$ & $\begin{array}{c}0.0 \\
(0.0)^{\mathrm{f}}\end{array}$ & $\begin{array}{c}0.0 \\
(0.0)^{\mathrm{e}}\end{array}$ & $\begin{array}{c}0.0 \\
(0.0)^{\mathrm{f}}\end{array}$ & $\begin{array}{c}0.0 \\
(0.0)^{\mathrm{f}}\end{array}$ & $\begin{array}{c}0.0 \\
(0.0)^{\mathrm{f}}\end{array}$ & $\begin{array}{c}0.0 \\
(0.0)^{\mathrm{e}}\end{array}$ & $\begin{array}{c}0.0 \\
(0.0)^{\mathrm{f}}\end{array}$ & $\begin{array}{c}0.0 \\
(0.0)^{\mathrm{d}}\end{array}$ & $\begin{array}{c}0.0 \\
(0.0)^{\mathrm{c}}\end{array}$ & $\begin{array}{c}0.0 \\
(0.0)^{\mathrm{e}}\end{array}$ \\
\hline SED & 2.79 & 2.85 & 2.48 & 3.51 & 2.38 & 2.49 & 2.89 & 2.97 & 4.82 & 2.13 & 3.88 & 4.43 & 3.03 & 4.10 & 4.6 \\
\hline $\begin{array}{l}\mathrm{CD} \\
(\mathrm{p}=0.05)\end{array}$ & 6.22 & 6.36 & 5.53 & 7.84 & 5.31 & 5.55 & 6.44 & 6.63 & 10.74 & 4.76 & 8.65 & 9.87 & 6.77 & 9.14 & 10.27 \\
\hline
\end{tabular}

*Values are mean of three replications

Values in parentheses are arc-sine transformed values

Mean values with various alphabets differ significantly by DMRT. 
All the five plant parts extract caused significant larval mortality. But the mortality was the maximum $(80.00 \%)$ when aqueous leaf extract at 10 per cent concentration was used on second instar larvae of $H$. armigera. The mortality rate was high in second instar larvae and gradually decreased in the third, fourth and fifth instars larvae. As the larvae became older, the mortality was nil in the fifth instar larvae.

In leaf extract, the mortality per cent got reduced from 83.33 to 76.66 per cent in third instar and 63.33 per cent in fourth instar. The flower extract was treated on different larval instars at various concentrations and from the results, it was observed that 10 per cent extract caused larval mortality to an extent of 66.66, 53.33 and 20.00 per cent on third, fourth and fifth instars respectively.

The root extract was less effective and caused 36.66 per cent mortality in second instar. This percentage got reduced when it was treated on the succeeding larval instars, namely third, fourth and fifth instar. The whole plant extract showed greater mortality next to leaf and flower extract at 10 per cent concentration and caused larval mortality to an extent of 63.33, 46.66 and 16.66 per cent on third, fourth and fifth instar.

As the concentration of plant parts extract increased, proportional larval mortality percentage was observed. Our study confirmed the efficacy of latex and extract components of calotropis and larval mortality increased with increasing concentration. Some pesticide compounds such as calotropin and calotoxin in the milkweed plant extracts may be the most important factors in causing mortality of Helicoverpa armigera larvae. Alaguchamy and Deivendran (2016) studied the larvicidal activity of aqueous extracts of Catharanthus roseus L (G) Don. were evaluated against gram pod borer Helicoverpa armigera (Lepidoptera: Noctuidae) which exhibited moderate larvicidal effects 2.60, $3.94,7.75,30.83,38.53$, and 63.34 per cent towards I, II, III, IV, V and VI instar larvae.

Simmonds et al., (1990) reported high antifeedancy (low ED50) for pure compounds isolated from different plants against the larvae of $H$. armigera. Janarthan et al., (1999) showed that 0.2 and $0.5 \%$ petroleum ether extracts of Parthenium histerophorus exhibited $100 \%$ feeding difference in $H$. armigera. Similarly, aqueous extracts of Calotropis procera and Datura stromonium have been shown to display about $90 \%$ feeding protection against $H$. armigera (Dodia et al., 1995).

Plant derived pesticides are eco-friendly, nontoxic to non-target organisms, non-persistent in nature, besides they are lees known to promote drug resistance. Application of botanical based bio-pesticides has been reported to have positive impacts on bollworm population management (Ramya et al., 2008).

From the results, it can be concluded that $C$. gigatea extracts possess good larvicidal activity against $H$. armigera and there is a scope for application of milky weed plant extracts in pest management programs.

\section{References}

Ahmad, M., 2007. Insecticide resistance mechanisms and their Management in Helicoverpa armigera (Hubner) - A review. J. Agric. Res., 45(4), 319-335.

Alaguchamy, A., and S. Deivendran. 2016. Larvicidal effect of catharanthus roseus 1 (g) don. leaf extracts against the larvae of Helicoverpa armigera (hubner). Int. J. of Zool and Applied Biosciences, 1(5): 231235.

Ballal, C. R., S. P. Singh, Sunil Joshi and N. S. Rao. 1998. Multicellular tray for rearing the larvae of Helicoverpa armigera (Hubner) 
(Lepidoptera:Noctuidae). Entomon, 23(4): 307-312.

Dodia, D. A., Patel, I. S., Pathak, A. R., 1995. Antifeedant properties of some indigenous plant extracts against larvae of Helicoverpa armigera. Pestol, 19: 21-22.

Harborne, J. B., 1988. Introduction to ecological biochemistry, II Edn. Academic Press, New York. 278pp.

Ignacimuthu, S., and Jayaraj, S. 2003. Ecofriendly approaches for sustainable pest management. Current Science, 84: 10-25.

Janardhan, R. S., Chitra, K. C., Kameswara, R. P and Subramaniyam, R. K., 1999. Antifeedant and insecticidal properties of certain plant extracts against Helicoverpa armigera. J. Insect Sci., 5: 163-164.

Kranthi, K. R., Jadhav, D. R., Wanjari, R. R., Shakir Ali and Russell, D. 2001. Carbonate and organophosphate resistance in cotton pests in India, 1995 to 1999. Bulletin of Entomological Research, 91: 37-46.

Pawar, C. S., 1998. Helicoverpa armigera a natural problem which needs a national policy and commitment for its management. Pestology, 22 (7): 51-59.

Ramasubramanyam, T., 2004. Magnitude, mechanism and management of pyrethroids resistance in Helicoverpa armigera. (Hubner) in Ind. J. of Ent, 16 -11.

Ramos, M. V., Bandeira G. P, de Freitas, C. D. T, Nogueira, N. A. P, Alencar, N. M. N, de Sousa, P. A. S, Carvalho A. F. U. 2006. Latex constituents from Calotropis procera (R. Br.) display toxicity upon egg hatching and larvae of Aedes aegypti (Linn). Mem Instit Oswaldo Cruz, 101(5): 503-10.

Ramya. S., Rajasekaran, C., Kalaivani, T., Sundararajan, G., and Jayakumararaj, R.,
2008. Biopesticidal effect of leaf extracts of Catharanthus roseus L (G) Don. On the larvae of gram pod borer, Helicoverpa armigera (Hubner). Ethnobotanical Leaflets, 12, 1096-1101.

Ravi, M., Santharam, G. and Sathiah, N. 2008. Ecofriendly management of tomato borer, Helicoverpa armigera (Hubner). Journal of Biopesticides, 1(2): $134-137$.

Reed, W., and Pawar, C. S. 1982. Heliothis: a global problem. In: Proceedings of the International Workshop on Heliothis Management (Reed, W. and Kumble, V.eds.) ICRISAT, Patancheru, India. 9-14 pp.

Sahayaraj, K., and M. Gabriel Paulraj. 1998. Effect of neem leaf extract on Amsacta albistriga Walker. Insect Environ, 4(2): 4243.

Sahayaraj, K., Ravi. C. 2007. Evaluation of reduviid predators and plant products against chosen groundnut pests. Arch. Phyto. Plant Pro. 40(4): 281-290.

Simmonds, M. S. J., Blaney, W. M., Fellows, F. E., 1990. Behavioral and electrophysiological study of antifeedant mechanisms associated with polyhydroxy alkaloids. J. Chem. Ecol.m 16: 3167-3196.

Vasantharaj David, B., 2008. Biotechnological approaches in IPM and their impact on environment. Journal of Biopesticides, 1(1): $1-5$.

Wink, K. M., and Guo, Y. Y. 1995. Production and application of phytochemicals from an agricultural perspective. In: Phytochemistry and Agriculture, Claredon Press Oxford, United Kingdom, 171-213 pp.

\section{How to cite this article:}

Prabhu, S., P. Priyadharshini and Thangamalar, A. 2017. Study on Larvicidal Effect of Different Plant Parts of Milk Weed Plant (Calotropis gigantea R. Br.) against Helicoverpa armigera. Int.J.Curr.Microbiol.App.Sci. 6(10): 655-660.

doi: https://doi.org/10.20546/ijcmas.2017.610.080 